\title{
ECONOMICAL AND SAFE METHOD OF GRANULAR MATERIAL STORAGE IN SILOS IN OFFSHORE PORT TERMINALS
}

\author{
Mateusz Sondej ${ }^{1}$ \\ Chandana Ratnayake ${ }^{2}$ \\ Michał Wójcik ${ }^{1}$ \\ ${ }^{1}$ Gdańsk University of Technology, Faculty of Civil and Environmental Engineering, Poland \\ ${ }^{2}$ Telemark Technological Research and Development Centre (Tel-Tek), Department of Powder Science and Technology (POSTEC), Norway
}

\begin{abstract}
The article discusses issues related with storage of granular materials in silos made of corrugated sheets and reinforced with vertical ribs. Advantages and disadvantages of these structures are named, and typical technological solutions used by largest silo producers are presented. Moreover, basic assumptions of Eurocode 3 are discussed in the context of determining the buckling load capacity of a ribbed jacket. Alternative methods are indicated to determine the silo stability using analytical and FEM based methods. General conclusions are formulated with respect to designing of silos made of corrugated sheets.
\end{abstract}

Keywords: silo, corrugated sheet, granular material, port terminal

\section{INTRODUCTION}

Bulk terminals in harbours are an important element of agricultural industry, involved in operations with various types of grains (wheat, barley, rye, rapeseed, etc.) and feed materials (soya meal, rape meal, beetroot pulp). The infrastructure of these terminals comprises silos, halls, conveyors, dryers, cleaners, mixers, laboratories, and ventilation and control systems. The basic structures used for cargo storage are largecapacity silos. The total capacity of typical terminals ranges from several tens to several hundreds of thousands of tonnes. For instance, the cubic capacity of flat-bottom silos at the Bytom Quay in the Port of Gdansk amounts to 55 thousand tonnes. The silos can be constructed of different materials, such as: steel, aluminium, reinforced concrete, brick, wood, or rarely used - flexible materials [1]. The cross-section shape of a silo is usually circular, due to favourable stress distributions (mainly of membrane type - without bending). However, in the cases of area limitation, it may turn out economically justified to use rectangular cross-sections. The silos can have a hopper for gravitational and direct cargo discharge to road or rail transport means. However, at larger diameters $\left(d_{c}>8 m\right)$ they are less effective due to large hopper loads. Large-scale structures usually rest directly on a foundation plate (flatbottom silos) and are emptied gravitationally or mechanically. In bulk terminals, the silos are most often grouped into batteries.

Reasonable choice of an optimal silo structure should take into consideration not only advantages and disadvantages of the structure alone, but also logistics, infrastructure, company's strategy, specific nature of stored materials, and climate (strong winds, earthquakes, thermal loads). Selecting an appropriate building material involves the analysis of numerous factors, such as: prices of materials, costs of building and operation, reliability and safety of the object, its durability, time of building, warranty, overall dimensions, and/or past experience of the potential owner.

At present, silos made of corrugated sheets (with horizontal folding) and reinforced with thin-walled columns, uniformly distributed around the silo perimeter and screwed to the sheets, are frequently used structural solutions of terminals used for granular material storage (Fig. 1). Their advantages include: economical steel consumption (low weight of the structure), prefabrication, 
easy and very fast assembly (from several to slightly more than ten days), aesthetics, higher buckling load capacity and lower sensitivity to initial geometric imperfections, compared to silos made of flat sheets, elasticity of the structure which ensures high resistance to earthquakes, possibility for modification of the existing object, or replacement of damaged elements, or total disassembly. On the other hand, basic disadvantages of these silo structures include susceptibility to corrosion, low resistance to negative pressure and explosions, and low load resistance at nonuniform material outflow. The diameters of silos made of corrugated sheets which are offered by various producers range from about $3.5 \mathrm{~m}$ to $42 \mathrm{~m}$. However, the majority of producers limit the overall dimensions of silos to $32 \mathrm{~m}$, mainly due to roof structure limitations. The slenderness of the produced silos, defined as the height-to-diameter ratio of the cylindrical part [2], is within $\lambda=0.4-3.5$. The slenderness ratios of large-diameter silos usually do not exceed $\lambda=1.0$. The thickness of corrugated sheets is usually from $0.7 \mathrm{~mm}$ to $3 \mathrm{~mm}$ (thicker sheets are obtained by uniting several sheets together). The height of the sheet fold is within $10<\mathrm{d}<20 \mathrm{~mm}$, while its length is within $68<\mathrm{d}<120 \mathrm{~mm}$ (Fig. 2). It is difficult to decide unambiguously which type of folding is better. The higher the sheet fold profile, the higher the bulk load capacity of the ribbed jacket. On the other hand, a high profile is characterized by higher wall roughness, which in turn increases the vertical load of the columns. The silo columns have usually the form of open thin-walled profiles made of higher-strength steel. Various cross-section shapes of folds are used to increase the resistance to local buckling, (Fig. 3). The shape of the column profile is usually selected such as to obtain high bending capacity, at simultaneous small sheet thickness (usually between $1.5 \mathrm{~mm}$ and $10 \mathrm{~mm}$ ) and taking into account assembly processes (for instance, possibility of economical storage and easy fixing to corrugated sheets). In axial compression conditions, the load capacity of the column cross-section varies from $50 \mathrm{kN}$ (Fig. 3j) to $2700 \mathrm{kN}$ (Fig. 3i). The jackets of small-size silos can maintain sufficient load capacity without vertical reinforcement $[3,4]$. For these solutions, it is more profitable to use corrugated sheets with relatively small folding.

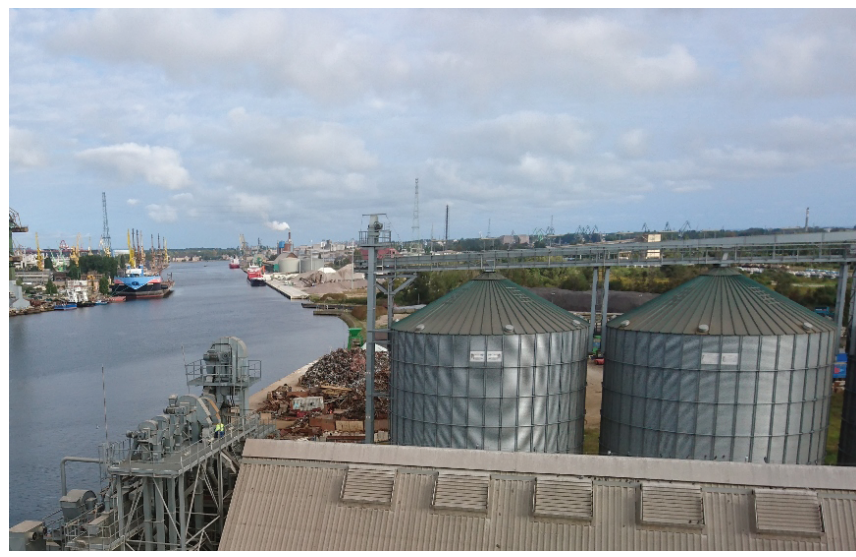

Fig. 1. Battery of steel silos in the Port of Gdansk

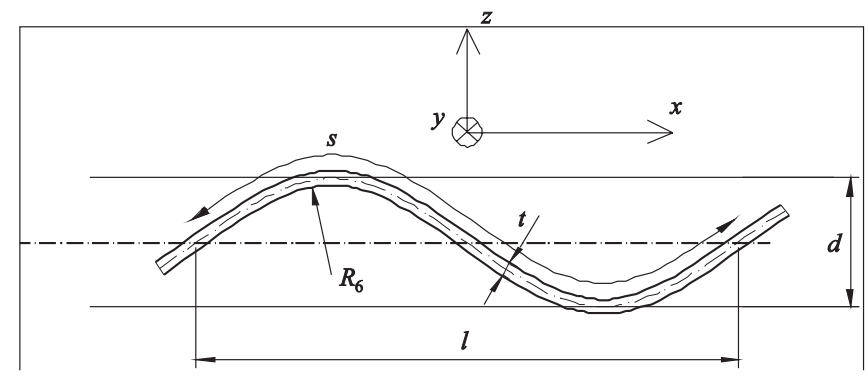

Fig. 2. Cross-section and geometric parameters of folding: $d$ - height of corrugated sheet, $l-$ width of fold, $R_{o}$ - local crest and hollow bending radius of the fold, $s$ - wave length, $t$ - sheet thickness
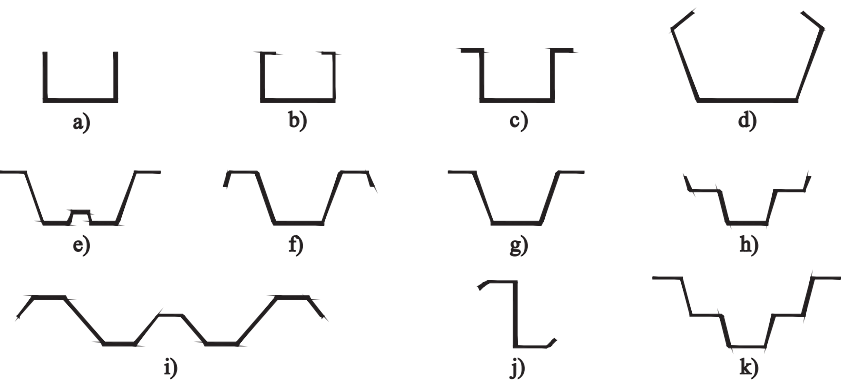

Fig. 3. Typical cross-sections of cold-formed column shapes which are fixed to horizontally corrugated silo sheets

The task of the silo structure is to carry loads, most of all coming from the stored granular material. The horizontal pressure generates circumferential tensile forces in the jacket, while the friction on the wall is the source of vertical compressive forces. The latter forces are carried by vertical columns, due to insufficient load capacity of corrugated sheets alone in this direction. The jacket ribbed in the above way is an orthotropic shell with very favourable strength parameters. The corrugated sheet serves a dual purpose: it carries the horizontal pressure of granular material and acts as elastic support for columns, protecting them against buckling. Unlike traditional silos made of flat sheets, here the silo wall only carries the tensile membrane forces, thanks to which its thickness and, consequently, weight are much smaller.

The stability loss of the structure is one of basic causes of failures in metal silos. It is noteworthy that the probability of failure in a silo is much greater than in other construction works. The silo failure can be not only a source of serious financial problems, but it also creates a potential threat to human life in direct vicinity of the silo. Despite numerous real experiments performed in silos [9] as well as numerical simulations [5-8], the main cause of silo failures is still insufficient knowledge on the complex behaviour of granular materials. The silos made of corrugated sheets are not completely free from failures [10], but they occur much more rarely, compared to failures in structures made of flat sheets. For structures whose failure would bring severe consequences, it can be reasonable to perform continuous measurements of forces in columns or jacket stresses, or direct pressure measurements. For instance, this type of monitoring is widely used in bridge structures [11] or public 
utility buildings $[12,13]$. The silo geometry assessment can be made using digital photogrammetry or laser scanning $[14,15]$ - including scanning from harbour canals and directly from the sea in the case of silos situated in harbours [16].

\section{LOAD CAPACITY OF SILOS MADE OF CORRUGATED SHEETS AND REINFORCED WITH COLUMNS}

Determining the buckling load capacity of a silo made of corrugated sheets and reinforced with columns around the perimeter is more difficult than for the silo made of flat sheets, as it requires the stability analysis of a ribbed shell, with functional load and stepwise thickness change of jacket and column walls. At present, designing of steel silos in based on the Eurocode 3 [2]. It is noteworthy that the past Polish norm PN-B-03202:1996 concerning silos did not provide any recommendations on how to check the buckling load capacity of a silo made of corrugated sheets. Part of silos which still work safely and without failure do not meet the requirements of current standards in force concerning the stability of silo structures [2], which may suggest that these requirements are too restrictive.

The standard Eurocode 3 [2] provides two concepts of determining the buckling load capacity, depending on the distance $\mathrm{d}_{\mathrm{s}}$ between vertical stiffeners. When this distance is smaller than the limit $d_{s, \max }$, the silo jacket is regarded as a shell with orthotropic properties, for which the critical buckling stress is calculated based on the Donnell-MushtariVlasov theory (Fig. 4). The limiting distance between the columns is defined as [2]:

$$
d_{s, \max }=k_{d x}\left(\frac{r^{2} D_{y}}{C_{y}}\right)^{0,25},
$$

where $C_{y}$ is the membrane stiffness in the direction of folding, $D_{y}$ is the bending stiffness in the direction of folding, $k_{d x}$ is the coefficient (recommended value $k_{d x}=7.4$ ), and $r$ is the silo radius.

The assumptions adopted in the so-called of equivalent orthotropic shell method are as follows: uniform and linear compressive load is applied to both cylinder edges (on the central surface); the stiffness of the jacket made of corrugated sheets and reinforced with ribs is averaged (smoothed) and constant along the entire height; the central surface of the equivalent shell coincides with that of the corrugated sheet; the eccentricity of ribs and stiffening rings is measured from the central surface; the edges of the cylindrical shell are not allowed to move in radial and circumferential directions; the forms of buckling are described by trigonometric functions [2].

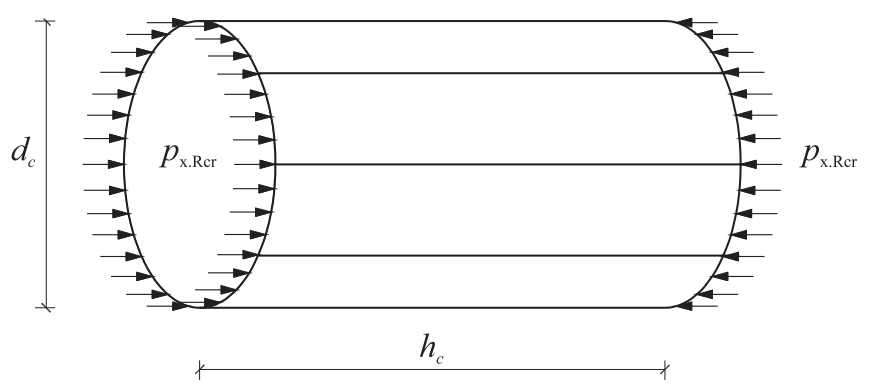

a)
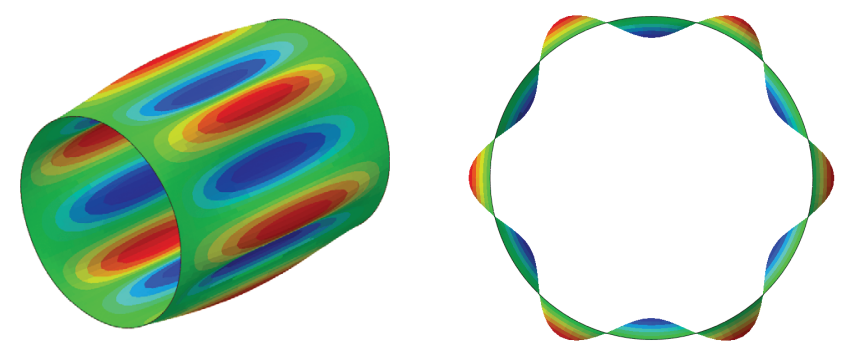

b)

Fig. 4. Cylindrical shell with orthotropic properties: a) geometry and loads, b) first form of buckling

When the distance between the columns is larger, i.e. when $d_{s}>d_{s . \max }$, the buckling load capacity is checked for a single vertical rib, based on the analogy to a compressed bar resting on an elastic foundation (Fig. 5). If more detailed calculations are not required, the critical force can be calculated from formula (2), which corresponds to the scheme shown in Fig. 5c:

$$
N_{b, R d}=2 \sqrt{E I_{y} K} / \gamma_{M 1},
$$

where $E I_{y}$ is the bending stiffness of the vertical rib, $K$ is the stiffness of the elastic foundation, and $\gamma_{M 1}$ is the safety factor.

Formula (2) was obtained for the following assumptions, illustrated in Fig. 5c: buckling of the column takes place only in the plane perpendicular to the silo wall (i.e. the corrugated sheet stiffens sufficiently the column in the tangent plane to the wall); the column is only loaded with the vertical force applied to its end; the column rests on elastic foundation along its length; the column is pinsupported at its ends; the solution does not depend on column height. The stepwise change of bending stiffness of ribs and jacket can be taken into account in a more detailed analysis, making use of the Finite Element Method (FEM) $[17,18,19]$, for instance. Due to relatively conservative values of buckling load capacities obtained from the model of bar resting on elastic foundation, the reducing effect of imperfections is omitted.

Simultaneous existence of these two completely different methods to calculate the buckling load capacity (depending on the distance between columns) leads to the discontinuity between them. The difference in buckling load capacity values 
at the boundary of applicability of these two methods can amount to as much as $700 \%$ [18], which testifies to the imperfection of the procedure given in the standard [2]. The results of calculations made using the FEM method [10, 17-19] confirm that the approach described in the standard is too conservative, especially for large distances between columns, when the applicable column stability analysis is based on the model of bar resting on elastic foundation. For some silo geometries characterised by small distances between columns, the standard-based load capacity of a silo without imperfections is nearly twice as low as that calculated using the FEM method. For large distances, this difference is even much more dramatic and can be as much as 10 times lower than the result obtained from FEM calculations. That is why the standard-based approach should not be applied to the latter case, due to the use of an oversimplified model leading to unrealistic results. The silos with buckling load capacity calculated based on the standards are unnecessarily oversized, by even as much as 2-3 times. The buckling load capacity of a silo made of corrugated sheets and reinforced with columns can be determined correctly using the approach described in [18], which proposes some modifications of the procedure calculating the buckling load capacity for silos with a relatively large distance between columns. The use of this method eliminates the load capacity jump at the applicability boundary. It also provides results close to those obtained using the FEM method. Nevertheless, a more detailed analysis which would take into account such important phenomena as local stability loss of thin-walled elements of the structure, or column bending at the support should be based on the FEM method which provides opportunities for broad static and dynamic, linear or nonlinear, analysis of buckling load capacity. The linear analysis is simple and can be used to assess critical loads, while the nonlinear analysis, based on the equilibrium path between load and strain, makes it possible to determine the critical load taking into account the effect of material and geometric nonlinearity [20].

\section{EFFECT OF GRANULAR MATERIAL ON BUCKLING LOAD CAPACITY OF A SILO}

Another disadvantage of the standard-based approach to determining critical forces in steel silos is neglecting the stabilised effect of stiffness of the stored granular material and the normal load on the load capacity of a cylindrical silo [21]. The results of experimental examination of silos have revealed that the buckling load capacity of a silo filled with granular material is much greater than that of an empty silo (in some cases this difference can even exceed 100\%). The numerical calculations $[3,4,21]$ made using an advanced model describing the behaviour of granular materials (non-local hypoplastic model [22-24]) have confirmed the positive effect of the presence of material on the load capacity of the full silo, compared to the empty one. The pressure of granular material reduces the amplitude of initial geometric imperfections. Moreover, the granular material act as lateral support for

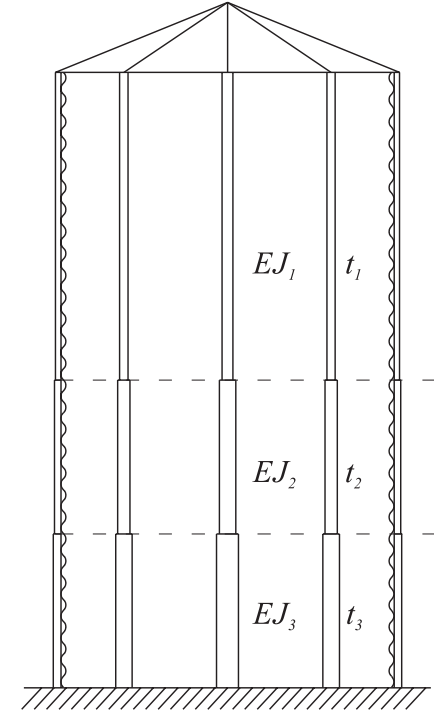

a)

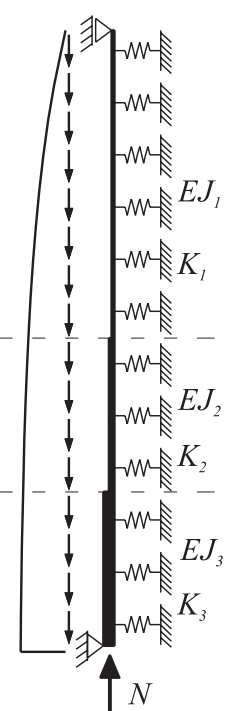

b)

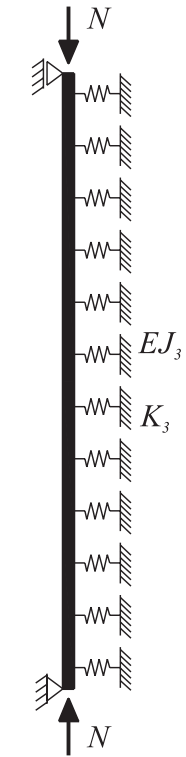

c)
Fig. 5. Single-column method: a) silo geometry; b) model of bar on elastic foundation; c) simplified model of column on elastic foundation, with constant stiffness along height (EI - bending stiffness of vertical rib, $K$ - stiffness of elastic foundation, $t$ - thickness of corrugated sheet, $N$ - force in column)

cylindrical silo walls, which move inward during the buckling process. The favourable effect of reinforcement in the cylindrical silo depends most of all on: stiffness of the granular material, flexibility of the wall, type and scale of initial geometric imperfections, yield point of the steel, and type of flow in the silo. As a rule, the buckling load capacity is higher for thinner walls, larger amplitudes of imperfections, and stiffer grains of the granular material [4]. At present, this effect is not taken into account in the standards.

\section{EFFECT OF GEOMETRIC IMPERFECTIONS}

Compared to silos made of flat sheets, the advantage of silo structures made of corrugated sheets and reinforced with columns is their relatively small susceptibility to initial geometric imperfections. Only the presence of larger geometric imperfections of silo walls, of several centimetres in size, (for instance $50 \mathrm{~mm}$, which is usually $30-100$-fold thickness of the corrugated sheet composing the wall) leads to noticeable decrease of buckling load capacity of the structure. Nevertheless, taking into account initial geometric imperfections in steel silo designing is of high importance $[25,26]$. Based on geodesically measured real imperfections [19], being the result of specific method of erection of a silo made of corrugated sheets and reinforced with columns (the silo erection begins with upper elements, which are successively elevated), we can observe that they differ considerably from the first form of buckling of the structure. Nevertheless, the effect of both types of imperfections on the buckling load capacity is similar, with differences not exceeding 20\% [19]. It is therefore advisable in FEM calculations to assume the imperfection having the shape of the first form of 
buckling (simpler application, compared to really measured imperfections) and the amplitude approximately equal to $5 \mathrm{~cm}$, to preserve an appropriate safety margin.

\section{SILOS MADE OF CORRUGATED SHEETS WITHOUT COLUMNS}

Although they are even more economical due to lower steel consumption, the silos made only of corrugated sheets are rather rarely used, since the absence of columns in combination with small vertical stiffness of corrugated sheets result in small load capacity of the silo with respect to vertical loads. At present, there are no realistic dimensioning methods for silos made solely of corrugated sheets. The standard Eurocode 3 contains a simple procedure for determining the load capacity of a corrugated sheet:

$$
n_{x, R k}=\max \left\{\frac{t^{2} f_{y}}{2 d} ; R_{\varphi} \frac{t}{r} f_{y}\right\},
$$

where:

$d$ is the height of fold, $R_{\varphi}$ is the local curvature radius of the corrugated sheet, $r$ is the silo radius, $t$ is the sheet thickness, and $f_{y}$ is the yield point of the steel. However, this procedure is very conservative, as it does not take into account the positive effect of granular material on silo's load capacity. According to this procedure, the load capacity of the silo made of corrugated sheets and loaded with granular material is sufficient for designing a small silo, of several meters in height and dimension. However, there are much larger silos made of corrugated sheets without columns which exist and function without problems, but for which the load capacity condition calculated from the standard is several times too low.

The numerical results [3] have revealed that empty silos made of corrugated sheets (without columns) are sensitive to wind and seismic loads, which generate additional vertical forces at the support and large displacements of the upper edge of the silo. However, it was observed that the presence of granular material has a huge positive effect on the load capacity of the silo during its filling. This effect increases with the decrease of wall thickness. The buckling load capacity also increases with the increase of grain stiffness and initial material densification. In contrast to the standard-based calculations performed to determine the load capacity of a sample silo made of corrugated sheets, of $2.67 \mathrm{~m}$ in diameter and sheet thickness of $1 \mathrm{~mm}$, which assessed this capacity as equal to $15 \%$ of sand load, the numerical calculations taking into account material stiffness have revealed that this silo can carry full sand load with large margin, of $230 \%$ [4]. For wheat, this margin was equal to $50 \%$. While for the silo made of flat sheets, the normal and tangential pressure distributions calculated using the FEM method [4] for the time of silo filling were similar to those based on the standard Eurocode 1 [27], for the corrugated sheets they differed significantly. The tangential pressure was much smaller, which resulted in much smaller reaction of the support, compared to that obtained using the standard-based approach. On the other hand, the normal pressure distribution during filling had the shape similar to hydrostatic, which gave higher pressure than that calculated based on the standard in the lower part of the silo [4]. Due to high elasticity of silo walls, the majority of vertical load is passed directly to the silo bottom, which creates a serious threat to silos with hoppers, the presence of which is not taken into account in standardbased dimensioning procedures.

\section{CONCLUSIONS}

Based on the performed theoretical and experimental examination, the following conclusions can be made:

- silos made of corrugated sheets and reinforced with vertical thin-walled columns around the perimeter are a safe and economical method of storage of various granular materials. When properly designed, these silos have twice as high buckling load capacity and twice as small weight as silos made of flat sheets,

- analytical dimensioning of silos made of corrugated sheets which is based on present silo standards is too simplified and uneconomical, especially for silos with relatively large distances between columns (it neglects real, three-dimensional operation of the entire structure), and should not be applied,

- silos made of corrugated sheets should be designed using the Finite Element Method (FEM), which provides opportunities for more realistic assessment of silo's buckling load capacity, compared to the standard-based calculations. This approach leads to massive material savings, at the same time making it possible to analyse in detail such important phenomena as, for instance, bending of silo columns at the foundation,

- the buckling load capacity can be approximately assessed using the modified procedure described in [18],

- the granular material in the silo significantly increases its load capacity. The scale of this increase depends on: elasticity of the structure, stiffness of the stored material, and type of flow, among other factors. The standard-based procedures neglect this fact,

- the FEM analysis of a silo structure should take into account initial geometric imperfections. For simplification purposes and to be on the safe side, it is advisable to assume the imperfection having the first global form of silo buckling and the amplitude equal to $5 \mathrm{~cm}$.

\section{REFERENCES}

1. Hotała E., Aniszczyk A.: Prototype silo structure with flaccid shell for biomass storage (in Polish). Materiały Budowlane 5 (2013) 52-54.

2. EN 1993-4-1, Eurocode 3. Design of Steel Structures. Part 4-1: Silos. Brussels: CEN, 2007. 
3. Kuczyńska N., Wójcik M., Tejchman J. Effect of bulk solid on strength of cylindrical corrugated silos during filling. Journal of Constructional Steel Research 115 (2015) 1-17, DOI: $10.1016 /$ j.jcsr.2015.08.002

4. Wójcik M., Tejchman J. Buckling analyses of metal cylindrical silos containing bulk solids during filling. Particulate Science and Technology 34, 4 (2016) 461-469, DOI: $10.1080 / 02726351.2016 .1185202$

5. Tejchman J.; Bauer E.; Wu W., Effect of fabric anisotropy on shear localization in sand during plane strain compression. Acta Mechanica 189, 1-2 (2007) 23-51.

6. Kozicki J., Niedostatkiewicz M., Tejchman A., Muhlhaus H. Discrete modelling results of a direct shear test for granular materials versus FE results. Granular Matter 15, 5 (2013) 607-627, DOI: 10.1007/s10035-013-0423-y

7. Kozicki J., Tejchman, A., Mühlhaus H.-B. Discrete simulations of a triaxial compression test for sand by DEM. International Journal for Numerical and Analytical Methods in Geomechanics, 18 (2014) 1923-1952, DOI: 10.1002/nag.2285

8. Nitka M., Tejchman J., Kozicki J., Lesniewska D. DEM analysis of micro-structural events within granular shear zones under passive earth pressure conditions. Granular Matter 17, 3 (2015), 325-343, DOI: 10.1007/s10035-015-0558-0

9. Wójcik M., Härtl J., Ooi J.Y., Rotter J.M., Ding S., Enstad G.G. Experimental investigation of flow pattern and wall pressure distribution in a silo with double-cone insert. Particle\&Particle System Characterization 24, 4-5 (2007) 296-303, DOI: 10.1002/ppsc.200601120

10. Iwicki P., Wójcik M., Tejchman J. Failure of cylindrical steel silos composed of corrugated sheets and columns and repair methods using a sensitivity analysis. Engineering Failure Analysis 18 (2011) 2064-2083, DOI: /10.1016/j. engfailanal.2011.06.013

11. Mariak A., Miśkiewicz M, Meronk B., Pyrzowski Ł. and Wilde K. Reference FEM model for SHM system of cable-stayed bridge in Rzeszów. Advances in Mechanics: Theoretical, Computational and Interdisciplinary Issues - Kleiber et al. (Eds), Taylor \& Francis Group, London (2016) 383-387

12. Miśkiewicz M., Pyrzowski Ł., Chróścielewski J., Wilde K.: Structural Health Monitoring of Composite Shell Footbridge for Its Design Validation. Proceedings 2016 Baltic Geodetic Congress (Geomatics)/ ed. Juan E. Guerrero Los Alamitos: IEEE Computer Society Order Number E5972 (2016) 228233, DOI: 10.1109/BGC.Geomatics.2016.48

13. Wilde, K., Miśkiewicz, M., Chróścielewski, J., SHM System of the Roof Structure of Sports Arena „Olivia”. Structural Health Monitoring II, DEStech Publ. Inc. (2013) 1745-1752,
14. Janowski A., Szulwic J., Zuk M. 3D modelling of liquid fuels base infrastructure for the purpose of visualization and geometrical analysis. SGEM2015 Conference Proceedings, ISBN 978-619-7105-31-5 / ISSN 1314-2704, June 18-24, 2015, Book1 Vol. 1, 753-764, 2015, DOI: 10.5593/SGEM2015/B11/ S6.096

15. Janowski A., Nagrodzka-Godycka K., Szulwic J., Ziolkowski P.: Remote sensing and photogrammetry techniques in diagnostics of concrete structures. Computers and Concrete 18, 3,405-420, DOI: 10.12989/cac.2016.18.3.405

16. Burdziakowski P., Janowski A., Kholodkov A. Matysik K., Matysik M., Przyborski M., Szulwic J., Tysiac P.: Maritime laser scanning as the source for spatial data. Polish Marit. Res. , 22, 4, 9-14, 2015, DOI: 10.1515/pomr-2015-0064

17. Wójcik M., Iwicki P., Tejchman J. 3D buckling analysis of a cylindrical metal bin composed of corrugated sheets strengthened by vertical stiffeners. Thin-Walled Struct. 49 (2011) 947-963, DOI:10.1016/j.tws.2011.03.010

18. Sondej M., Iwicki P., Tejchman J., Wójcik M. Critical assessment of Eurocode approach to stability of metal cylindrical silos with corrugated walls and vertical stiffeners. Thin-Walled Structures 95 (2015) 335-346, DOI: 10.1016/j. tws.2015.07.015

19. Sondej M., Iwicki P., Wójcik M., Tejchman J. Stability analyses of a cylindrical steel silo with corrugated sheets and columns. Steel and Composite Structures 20, 1 (2016) 147-166, DOI : $10.12989 /$ scs.2016.20.1.147

20. Iwicki P., Tejchman A., Chróścielewski J.: Dynamic FE simulations of buckling process in thin-walled cylindrical metal silos. Thin-Walled Structures 84 (2014) 344-359, DOI: 10.1016/j.tws.2014.07.011

21. Wójcik M., Tejchman J. Simulation of buckling process of cylindrical metal silos with flat sheets containing bulk solids. Thin-Walled Structures 93 (2015) 122-136, DOI: 10.1016/j. tws.2015.02.025

22. Tejchman J., Wójcik M.: Modeling of shear localization during confined granular flow in silos within non-local hypoplasticity. Powder Technology 192, 3 (2009), 298-310, DOI: 10.1016/j.powtec.2009.01.021

23. Tejchman J., Niemunis A.: FE-studies on shear localization in an anisotropic micro-polar hypoplastic granular material. Granular Matter 8, 3-4 (2006), DOI: 10.1007/ s10035-006-0009-z

24. Tejchman J., Wu W.: Non-coaxiality and stress-dilatancy rule in granular materials: FE investigation within micropolar hypoplasticity, International Journal for Numerical and Analytical Methods in Geomechanics 33, 1 (2009) 117-142, 
25. Bielewicz E, Górski J.: Shells with random geometric imperfections simulation-based approach. International Journal of Non-Linear Mechanics 37, 4-5 (2002) 777-784, DOI: 10.1016/S0020-7462(01)00098-1

26. Górski J., Mikulski T., Oziębło M., Winkelmann K.: Effect of geometric imperfections on aluminum silo capacities Stahlbau 84, 1 (2015) 52-57, DOI: 10.1002/stab.201510224

27. EN 1991-4, Eurocode 1: Actions on Structures. Part 4: Silos and Tanks. General Principles and Actions for the Structural Design of Tanks and Silos, 2009.

\section{CONTACT WITH THE AUTHOR}

\section{Mateusz Sondej}

Gdańsk University of Technology

Faculty of Civil and Environmental Engineering

G. Narutowicza 11/12

80-233 Gdańsk

Poland

\section{Chandana Ratnayake}

Telemark Technological Research and Development Centre (Tel-Tek),

Department of Powder Science and Technology

(POSTEC), Porsgrunn

\section{NORWAY}

\section{Michał Wójcik}

Gdańsk University of Technology

Faculty of Civil and Environmental Engineering

G. Narutowicza 11/12

80-233 Gdańsk

Poland 